University of Wollongong

Research Online

Faculty of Engineering and Information

Faculty of Engineering and Information

Sciences - Papers: Part A

Sciences

$1-1-2016$

Drained and undrained shear behavior of compacted coal wash

Ana Heitor

University of Wollongong, aheitor@uow.edu.au

Buddhima Indraratna

University of Wollongong, indra@uow.edu.au

Chazath Kaliboullah

University of Wollongong, cik975@uowmail.edu.au

Cholachat Rujikiatkamjorn

University of Wollongong, cholacha@uow.edu.au

Geoffrey McIntosh

Douglas Partners Pty Ltd

Follow this and additional works at: https://ro.uow.edu.au/eispapers

Part of the Engineering Commons, and the Science and Technology Studies Commons

Research Online is the open access institutional repository for the University of Wollongong. For further information contact the UOW Library: research-pubs@uow.edu.au 


\title{
Drained and undrained shear behavior of compacted coal wash
}

\begin{abstract}
Coal wash is a granular waste material that is readily available in the vicinity of coal mining operations. While its potential use in structural fills has been recognized in the past, the effects of particle breakage on the geomechanical performance of the material have not been thoroughly investigated. In this paper, an experimental study on a selected coal wash is undertaken to characterize the influence of compaction and particle breakage on its corresponding stress-strain behavior. Particular emphasis is given to the role of compaction energy level and associated breakage incurred during compaction on the drained and undrained shearing behavior. The incidence of particle breakage for undrained and drained shearing was observed to be different, which in turn had a strong influence in the yielding behavior and the critical state. Furthermore, the critical state conditions for coal wash seem to be better described through a threedimensional surface incorporating the effect of breakage.
\end{abstract}

\section{Keywords}

wash, compacted, behavior, coal, shear, undrained, drained

Disciplines

Engineering | Science and Technology Studies

\section{Publication Details}

Heitor, A., Indraratna, B., Kaliboullah, C. I., Rujikiatkamjorn, C. \& McIntosh, G. W. (2016). Drained and undrained shear behavior of compacted coal wash. Journal of Geotechnical and Geoenvironmental Engineering, 142 (5), 04016006-1-04016006-10. 


\title{
Drained and undrained shear behaviour of compacted coalwash
}

\author{
Ana Heitor \\ LicEng (Lisbon), MEng (Kyoto), PhD(Wollongong) \\ Lecturer, Civil Engineering, Centre for Geomechanics and Railway Engineering, , \\ University of Wollongong, Wollongong, NSW 2522, Australia
}

\begin{abstract}
Buddhima Indraratna $†$
BSc (Hons, London), MSc (London), PhD (Alberta), FTSE, FIEAust, FASCE, FGS, FAusIMM, DIC, CEng, CPEng

Senior Professor of Civil Engineering,

Director, Centre for Geomechanics and Railway Engineering, University of Wollongong, Wollongong, NSW 2522, Australia
\end{abstract}

\section{Chazath I. Kaliboullah}

BTech (Pondicherry), MEng (Chennai)

PhD candidate, Centre for Geomechanics and Railway Engineering, University of Wollongong, Wollongong, NSW 2522, Australia

\section{Cholachat Rujikiatkamjorn}

BEng (Hons), MEng (AIT), PhD (Wollongong)

Associate Professor, Civil Engineering, Centre for Geomechanics and Railway Engineering, University of Wollongong, Wollongong, NSW 2522, Australia

\section{Geoffrey W McIntosh}

BEng (Hons), ME (Hons), FIEAust CPEng

Principal, Douglas Partners Pty Ltd, Wollongong office, Unanderra, NSW 2526, Australia

†Author for correspondence:

Prof. Buddhima Indraratna

Faculty of Engineering and Information Sciences,

University of Wollongong, Wollongong, NSW 2522

AUSTRALIA

Ph: +61 242523046

Fax: +61 242213238

Email: indra@uow.edu.au

To be submitted to: Journal of Geotechnical and Geoenvironmental Engineering 


\title{
Drained and undrained shear behaviour of compacted coalwash
}

\author{
Ana Heitor ${ }^{1}$, Buddhima Indraratna ${ }^{2}$, Chazath I.Kaliboullah ${ }^{3}$, Cholachat \\ Rujikiatkamjorn ${ }^{4}$ and Geoffrey W McIntosh ${ }^{5}$
}

\footnotetext{
${ }^{1}$ Lecturer, Centre for Geomechanics and Railway Engineering, Univ. of Wollongong, Wollongong City, NSW 2522, Australia. E-mail: aheitor@uow.edu.au.

${ }^{2}$ Senior Professor of Civil Engineering, Director of the Centre for Geomechanics and Railway Engineering, Univ. of Wollongong, Wollongong City, NSW 2522, Australia E-mail: indra@uow.edu.au (corresponding author)

${ }^{3} \mathrm{PhD}$ Candidate, Centre for Geomechanics and Railway Engineering, Univ. of Wollongong, Wollongong City, NSW 2522, Australia. E-mail: cik975@uow.edu.au

${ }^{4} \mathrm{~A} /$ Professor, Centre for Geomechanics and Railway Engineering, Univ. of Wollongong, Wollongong City, NSW 2522, Australia E-mail: cholacha@uow.edu.au

${ }^{5}$ Principal, Douglas Partners Pty Ltd, Unanderra NSW 2526, Australia E-mail: Geoff.McIntosh@douglaspartners.com.au
}

\begin{abstract}
Coalwash is a granular waste material that is readily available in the vicinity of coal mining operations. While its potential use in structural fills has been recognised in the past, the effects of particle breakage on the geomechanical performance of the material have not been thoroughly investigated. In this paper, an experimental study on a selected coalwash is undertaken to characterize the influence of compaction and particle breakage on its corresponding stress-strain behaviour. Particular emphasis is given to the role of compaction energy level and associated breakage incurred during compaction on the drained and undrained shearing behaviour. The incidence of particle breakage for undrained and drained shearing was observed to be different, which in turn had a strong influence in the yielding behaviour and the critical state. Furthermore, the critical state conditions for coalwash seem to be better described through a three dimensional surface incorporating the effect of breakage.
\end{abstract}

CE Database subject headings: coalwash; compaction; particle breakage; undrained and drained shear behaviour 


\section{Introduction}

Coal mining operations in Australia alone generate a few hundreds of millions of tonnes per year of colliery spoil or coal washery reject, which consists of about $80 \%$ coarse-grained coalwash and 20\% fine-grained tailings (Leventhal, 1996). The potential effective reuse and recycling of granular wastes such as coalwash as a fill material for earthwork construction, embankments and/or structural fill materials in port expansion projects has important advantages, both from economic and environmental perspectives (e.g. Indraratna et al., 1994). While past studies have focussed on the characterization of the geotechnical properties of coal mining wastes and their associated particle breakage (e.g. Kettle, 1983; Seddon et al., 1987; Montgomery, 1990; Canibano et al., 1990; Skarżyńska, 1995 and Rujikiatkamjorn et al., 2013), less emphasis has been placed on investigating the impact of the level of relative compaction on the stress-strain behaviour with respect to particle breakage. Furthermore, although Leventhal, (1996), Indraratna et al. (1994) and more recently Fityus et al. (2008) reported the suitability of coalwash as structural fill on the basis of its shear strength, the impact of breakage (during compaction and shearing) was not investigated. This is undoubtedly important as during compaction significant breakage occurs (i.e. Rujikiatkamjorn et al., 2013, Kaliboullah et al., 2015) which in turn likely influences the shear strength and deformation characteristics.

The quantification of breakage during shearing is also imperative to understand the role of the particle degradation on shear strength behaviour of granular materials. While the particle degradation influence on the shearing behaviour has been relatively well established for granular materials such as sands, limited studies have reported the behaviour for granular wastes such as coalwash. Been et al (1991) reported the existence of a bilinear critical state line (CSL) for drained and undrained 
shearing of sands, and Yamamuro and Lade (1996) showed that the sharp change in slope in the CSL observed was associated with a larger incidence of particle breakage. Similar observations were also reported by Bedin et al. (2012) for mine tailings. In addition, Russell and Khalili (2004) identified a third linear segment of the CSL in which compression was the governing deformation mechanism. Furthermore, the numerical study by Wood and Maeda (2008) showed that the location of CSL is strongly associated with the evolution of particle grading during shearing and suggested the existence of a possible critical state surface described by the change in specific volume and compression slope.

Given that coalwash is a granular material having high breakage potential, its behaviour as a structural fill needs to be examined under expected site conditions in order to avoid undesirable field performance upon loading. Furthermore, while the material has been accredited for landfilling by the NSW Environment Protection Authority (EPA) and used in the Wollongong region quite freely for example by local councils, there is only anecdotal experience and scientifically documented practices which have monitored its engineering performance. Further, the geomechanical behaviour upon compaction and shearing has not been systematically addressed, and with the expansion of local harbours and large areas of landfilling for future transport infrastructure etc., the engineering performance of coalwash needs to be examined in greater depth. In this paper, an experimental study on a selected compacted coalwash (80:20 coarse to tailings ratio) is undertaken to characterize the influence of compaction and particle breakage on its corresponding stress-strain behaviour. The results presented are applicable for coalwash having tailings content under $20 \%$, which is suitable for use as structural fill (e.g. Port reclamation). The coarse fraction to fine tailings ratio of the coalwash can vary considerably, however, the acceptance 
criteria in Port Kembla reclamation work was stringent. The material was specially graded and screened through industrial sieves, such that the finer fraction was controlled to eliminate adverse effects on the overall shear behaviour and angle of shearing resistance, i.e. less than $20 \%$ tailings.

\section{Materials}

The material selected for this study is a Dendrobium coalwash that has been used extensively as a land reclamation fill and retaining wall backfill in the Illawarra region (NSW, Australia). The Dendrobium coalwash produced in the coal mining areas surrounding the City of Wollongong is predominantly composed quartz and residual coal, with illite and kaolinite as the main clay minerals. Trace quantities of calcite, pyrites and sulphur were also detected in the x-ray diffraction analysis. The chemical composition is given in Table 1 . The aggregates compose of both angular and relatively flaky grains, and coalwash typically exhibits dual porosity (Lu and Do, 1992). For the selected coalwash the maximum particle size was less than $100 \mathrm{~mm}$. To enable the testing of small specimens in triaxial conditions in the laboratory, a parallel gradation to the prototype particle size distribution (PSD) was adopted to exploit the geomechanical similitude (i.e. parallel gradation technique, e.g. Indraratna et al., 1993) while acknowledging the a potential impact of the shear behaviour of having to use reduced particle sizes and larger amount of fines.. The particle size distribution (PSD) adopted is shown in Fig. 1, and it includes 6\% gravel, 75\% sand, $17 \%$ silt and $2 \%$ clay. As this specially screened material for industry applications did not have significant clay content (less than 3\%), the impact of clay mineralogy was not considered within the scope of this study. The coalwash has a plasticity index of $10.7 \%$, a liquid limit of $27.7 \%$ and a specific gravity of 2.23 ; thus, it can be classified as clayey sand or SC (Unified Soil Classification System). The properties of 
coalwash are elaborated in detail by Rujikiatkamjorn et al. (2013), Chiaro et al. (2014) and Tasalloti et al. (2015). The curves representing the coalwash tailings (Indraratna et al., 1994) and the arbitrary boundary of maximum permissible breakage are also shown in Fig. 1 for comparison.

To evaluate particle breakage, a method that quantifies the changes in particle size distribution was adopted (see Fig. 1, Indraratna et al., 2005). Here, the arbitrary boundary of maximum breakage is fixed depending on the grading of the specimen after shearing. The minimum and the maximum particle sizes were assumed to be $0.01 \mathrm{~mm}$ and $5 \mathrm{~mm}$, respectively. This corresponds to 95\% passing of the specimen gradation (Fig. 1). The compaction induced breakage occurring during specimen preparation at various compaction efforts, expressed as the breakage index $\left(B_{c}\right)$ is shown in Table 2. The associated shift in particle size gradation is shown in Fig. 2a. It can be observed that the amount of breakage occurring during the compaction process can be directly related to the relative compaction (RC) level. The RC levels adopted were computed based on laboratory standard Proctor dry unit weights. Although the PSD curves representing RC levels of 90, 95 and 100\% nearly coincide for particles sizes of less than 0.6 and exceeding $5 \mathrm{~mm}$, there are noticeable differences between 0.6 to $5 \mathrm{~mm}$, particularly around $0.3 \mathrm{~mm}$ (Fig. 2a). The higher the RC level is, the larger is the percentage of particles ranging from 0.6 to $5 \mathrm{~mm}$ size, indicating that a higher densification is achieved for higher RC levels.

Particle breakage is very significant not only during compaction, but also during compression and shearing stages. Fig. 2(b) shows an example of the change in PSD curves of specimens compacted at a RC level of $100 \%$ determined at the end of three triaxial compression undrained tests conducted at different effective confining pressures. The PSD curves, representing the initial and after compaction gradations 
for the RC level of $100 \%$ are also shown for comparison. The higher the effective confining pressure is, the broader the particle gradation is, which indicates a larger breakage incidence. The predominant particle size range is however different than that of compaction with significant PSD shift towards the lower particles sizes (0.02 to $2 \mathrm{~mm}$ ). The PSD after the compression/consolidation stage was not monitored because, the volumetric strains observed for the adopted confining pressure range were small, hence it was assumed that breakage related to compression/consolidation would not be significant. Furthermore, if the PSD had been measured after compression by sieving, then due to sample disturbance the specimens could not have been prepared to the original structure (grain assembly) for the subsequent shearing stage.

The structure of compacted coalwash was examined using a scanning electron microscope (SEM) JEOL JSM-6490LA housed at the microscopy facility of the University of Wollongong. This SEM can operate at low vacuum, which allows the testing of specimens in a moist condition, thus avoiding undesirable microstructural damage that can results from the drying process. The micrographs of compacted coalwash (Figure 3) revealed that the particles are predominantly angular and confirmed the existence of different pore sizes ranging from approximately $200 \mu \mathrm{m}$ (macroporosity, Fig. 3a) to less than $1 \mu \mathrm{m}$ (microporosity, Fig. 3d). These observations are consistent with the earlier microstructural studies reported by Lu and Do (1992) and Indraratna et al. (1994). The presence of micropores is further supported by the specific gravity (SG) results of the selected compacted coalwash specimen $(\mathrm{SG}=2.23)$ and individual $5 \mathrm{~mm}$ coalwash particles $(\mathrm{SG}=2.05)$. 


\section{Testing program}

The coalwash material was oven dried to $50^{\circ} \mathrm{C}$. Upon mixing with the required amount of water, any visible lumps were disaggregated and the mixture was kept overnight under constant temperature $\left(20 \pm 2^{\circ} \mathrm{C}\right)$ and humidity $(68 \%)$ conditions for moisture equilibration. The compaction characteristics were established using the standard Proctor compaction test (AS 1289.5.1.1, 2003). For an energy level equivalent to standard Proctor, the maximum dry unit weight and the optimum moisture content were $16.5 \mathrm{kN} / \mathrm{m}^{3}$ and $12.5 \%$, respectively.

For the purpose of preparing coalwash specimens at various relative compaction levels, the applied energy was varied while maintaining the moisture content at $10 \%$. This moisture content was selected because the average moisture content of the stockpiles at Port Kembla, NSW was measured to be in the range of 9 - 11\%. Four different levels of compaction energy $\left(85 \mathrm{~kJ} / \mathrm{m}^{3}, 170 \mathrm{~kJ} / \mathrm{m}^{3}, 341 \mathrm{~kJ} / \mathrm{m}^{3}\right.$ and 681 $\mathrm{kJ} / \mathrm{m}^{3}$ ) were considered corresponding to $85 \%$, $90 \%$, $95 \%$ and $100 \%$ of the standard Proctor maximum dry unit weight, respectively. The specimens were prepared with dimensions of $50 \mathrm{~mm}$ in diameter and $101.5 \mathrm{~mm}$ in height by dynamic compaction (impact-type) following a procedure described by Heitor et al. (2013). The required amount of moisture was added to the samples and specimens were compacted with the specified energy level in three layers of approximately $3.5 \mathrm{~cm}$ height. The weight of the wet sample was closely monitored $( \pm 2 \mathrm{~g}$ ) to ensure the specimens attained the specified compacted dry unit weight. The dry unit weight and associated void ratio for the relative compaction levels adopted are given in Table 2.

A series of triaxial drained (12), undrained (16), isotropic compression (3) and stress path (14) tests were performed to evaluate the stress-strain and yielding behaviour of the compacted coalwash and the associated particle breakage (Table 3). 
The tests were conducted in a standard triaxial apparatus and comprised three distinct stages: saturation, consolidation and shearing. During the saturation stage, the air was first displaced with $\mathrm{CO}_{2}$, and a back pressure of $150 \mathrm{kPa}$ was applied to the bottom pedestal. Typically, this procedure yielded Skempton's B-value exceeding 0.98 . Following isotropic compression to the desired mean effective pressure, the shearing stage was conducted for both drained and undrained conditions, at a constant strain rate of $0.1 \mathrm{~mm} / \mathrm{min}$. For the drained tests, the volume change was monitored from the water exchanged in the specimens during shearing, whereas the volume change during undrained shearing was measured using a water pressure volume controller (accuracy of $1 \mathrm{~mm}^{3}$ ) connected to the triaxial cell, following the procedure outlined by Garga and Zhang (1997). A summary of the testing program is given in Table 3. Additional tests were conducted to verify the repeatability of the test data (i.e. Table 3: D6 and D6a).

\section{Stress-strain behaviour and associated breakage}

The drained compression response for different levels of confining pressure and relative compaction level of $90 \%$ and $100 \%$ is shown in Fig.4a and 4c, in terms of deviator stress $(q)$ and axial strain $\left(\varepsilon_{1}\right)$ together with the yield points. For determining the yield points, the procedure suggested by Karner et al. (2003) was adopted. The yield point is interpreted as the point that corresponds to a change in slope of the volumetric strain with mean effective pressure plot. The data for RC level of $95 \%$ is included as supplemental data. For the same RC level, the stress-strain behaviour of the compacted coalwash was found to depend on the effective confining pressure. As expected, the initial slope of the stress-strain curve increases with the increase in confining pressure. For low confining pressure typically less than $50 \mathrm{kPa}$, the material 
exhibits slight post-peak softening whereas for higher confining pressure, typically exceeding $100 \mathrm{kPa}$, it displays a more pronounced strain hardening response.

While with increasing RC levels, the stress-strain response for the same confining pressure changes from a predominately strain hardening to a post-peak softening, the specimens prepared at different RC levels (i.e. $90 \%, 95 \%$ and $100 \%$ ) converge towards approximately the same residual deviator stress. This indicates that the coalwash shear response for different RC levels resembles that of loose or dense sand specimens.

The associated volumetric behaviour is shown in Fig. $4 \mathrm{~b}$ and $4 \mathrm{~d}$. It can be observed that for RC level of $90 \%$ the coalwash specimens exhibit mainly compressive behaviour whereas for RC levels of $95 \%$ and $100 \%$ dilation is observed for the lower effective confining pressures (i.e. 25 and 50kPa). At larger strains, all specimens reached a relatively constant volume state, although this was more evident for those specimens prepared at RC levels of $95 \%$ and $100 \%$. The existence of a constant volume or critical state for granular materials displaying particle degradation during shearing is often challenged because continued shearing promotes additional particle breakage even at large strains. However, the results shown in Fig. 4b and 4d indicate that a critical state can be achieved for coalwash. Typically, strain localization was not visually observed, except for RC100 specimen tested at $50 \mathrm{kPa}$ confining pressure. Thus, the overall interpretation of CSL still holds. For instance, for the specimens prepared at RC level of $90 \%$, critical state is approached for axial strains of about $35 \%$ while for a RC level of $100 \%$, critical state is attained for axial strains in the order of $20 \%$. In the specimens compacted at $90 \%$ relative compaction and tested at high effective confining pressure (i.e. 100 and $150 \mathrm{kPa}$ ), critical state was 
not reached due to the limitation of triaxial apparatus (i.e. in terms of maximum axial strain attained).

The behaviour of compacted coalwash specimens prepared at different RC levels and tested under undrained shearing is shown in Fig. 5. The changes of pore water pressure and volumetric strain with axial strain are shown in Fig. 5b and 5e and Fig 5c and 5f, respectively. As expected, an increase in the initial confining pressure results in an increase of the pore water pressure, which becomes relatively constant when axial strains exceed 5\%. The volumetric strain responses shown in Fig. 5c and5f are complementary to the effect of breakage during undrained shearing that is possibly associated with pore fluid compression (Garga and Zhang, 1997) and the progressive saturation of the micropores of coalwash (Lu and Do, 1992). Typically, no volumetric strains are observed during undrained shearing of fine grained materials, but for coalwash with inadequate saturation of the particle micropores this is not the case. Although, the volumetric strains measured are mainly associated with a contraction response (i.e. water intrudes the micropores as the pore water pressure develops), in some cases dilation is observed. For those dilating specimens, a corresponding drop in the pore water pressure is also detected (i.e. specimens prepared at RC of $100 \%$ and tested under confining pressures of 50 and $200 \mathrm{kPa}$ ). The results shown in Figs. 5 a to $5 \mathrm{f}$ reveal that for a given effective confining pressure, the deviator stress increases with the increase of relative compaction, while the excess pore water pressure decreases.

To examine the yielding behaviour of coalwash, additional extension (constant $p^{\prime}$ ) tests were conducted. The mean effective stress (p') is computed as $p^{\prime}=\left(\sigma_{1}+\right.$ $\left.2 \sigma_{3}\right) / 3$. These results are shown in the supplemental data section. 
The variation of the stress ratio ( $\left.q / p^{\prime}\right)$ with axial strain of both undrained and drained compression tests indicate that the stress ratio swiftly converges to a constant value once a certain level of axial strain is exceeded. The stress ratio relationship at or approaching critical state is better illustrated in Fig. 6. An interesting observation is that the stress ratio $\left(q / p^{\prime}\right)$ at or approaching the critical state defines a unique gradient $\left(M_{c}=1.41\right)$ for the same line capturing both the drained and undrained test data. Furthermore, it appears that the critical state gradient is independent of the initial level of RC, as all specimens compacted at RC = 90\%, 95\% and 100\% (Fig. 6) define the same relationship, which is to be expected for coalwash. Along this critical state line, the corresponding friction angle $\left(\phi_{\mathrm{cs}}\right)$ is $35^{\circ}$.

For the specimens prepared at RC level of $90 \%$ and tested at high effective confining pressures that did not reached critical state at axial strains of $35 \%$, an extrapolation method proposed by Carrera et al. (2011) was adopted to estimate the location of critical state.

While the critical state of all specimens defines a unique line in the $q$ - $p$ ' plane (Fig. 6), in the compression plane $\left(e-\ln p^{\prime}\right)$ different RC levels are represented by distinct lines (Fig. 7a). From the drained tests results, a family of critical state lines (CSL) can be defined for the specimens prepared at different RC levels (Fig. 7a). While this behaviour might not seem intuitive at first, it can be explained if the initial particle size gradation is taken into account (Fig. 2a). The broader the gradation resulting from the compaction process is, the denser the particle packing and the lower limiting value of void ratio. Hence the location of drained CSL is directly associated with the compaction energy level adopted, that is, the position moves towards the smaller void ratios for larger compaction energy levels. Similar observations have been reported for sands prepared with different initial grading 
(Kikumoto et al., 2010) and by past numerical studies conducted by Wood and Maeda (2008).

The CSL for undrained shearing was found to be non-linear across the $e-\ln p^{\prime}$ plane, typically including three different stress regions, each having unique deformation characteristics marked by noticeable changes in the slope of the CSL line, at mean effective stresses of $127 \mathrm{kPa}$ and $187 \mathrm{kPa}$. For mean effective pressures larger than $127 \mathrm{kPa}$, there is a sharp decrease in the void ratio for a relatively small change in $p^{\prime}$, likely associated with significant particle breakage and recompression behaviour at higher stresses. The different stress regions can also be observed in Fig. 7b, where the ratio of total breakage index $\left(B_{t}\right)$ over the amount of compaction induced breakage $\left(B_{c}\right)$ with the logarithm of mean effective stress ( $\left.p^{\prime}\right)$ is shown. The $B_{t}$ index refers to the total breakage including that incurred during both compaction and shearing whereas $B_{c}$ refers only to the breakage occurring during compaction.

In the lower mean effective stress range $\left(p^{\prime}<50 \mathrm{kPa}\right), B_{t} / B_{c}$ for both drained and undrained shearing remains approximately at value of 1.1 (Fig. 7b). This suggests that the compaction induced breakage is more significant than that of compression and shearing. However, for larger $p$ ' values, while a linear relation between the $B_{t} / B_{c}$ and $\ln p^{\prime}$ is obtained for drained shearing, a tri-linear relationship is observed for undrained shearing, with bisections at $p^{\prime}=127 \mathrm{kPa}$ and $187 \mathrm{kPa}$. At a stress level of $127 \mathrm{kPa}$, the slope of the $B_{t} / B_{c}$ vs $\ln p$ ' line changes abruptly and becomes considerably steeper, suggesting increased particle breakage during compression and shearing. This stress level may be interpreted as a critical breakage stress $\left(p_{c b}^{\prime}\right)$ and coincidently corresponds to the stress level for which the transition in the undrained CSL is observed (Fig. 7a). In addition, while a single transition in slope in the CSL of other granular materials has been attributed to particle breakage or crushing from a 
qualitative standpoint, i.e. gold tailings at $p_{c b}^{\prime}=225 \mathrm{kPa}$ (Bedin et al., 2012) and cambria sand at $p_{c b}^{\prime}=4 M P a$ (Yamamuro and Lade, 1996), only limited studies have demonstrated quantitatively the effects of breakage. Another aspect illustrated in Fig. 7 is the second transition at $p^{\prime}=187 \mathrm{kPa}$ on the undrained CSL (Fig. 7a), and for the slope of the line representing the breakage indices $\left(B_{t} / B_{c}\right)$ as shown in Fig. $7 \mathrm{~b}$. At higher mean effective stresses, while the incidence of particle breakage is still significant, the main deformation mechanism is likely to be associated with further compression, the rate of which decreases upon increased loading. The results of the drained tests (i.e. Fig.4 and Fig. 7b) show that the particle breakage increases with increase in mean effective confining pressure. In this range, the volumetric behaviour changes from mainly dilation at low confining pressure to compression with the increasing confining pressure. Past experimental and DEM studies on coarse granular materials conducted at University of Wollongong have shown that in the early dilation stage, particle degradation is mainly associated with the breakage of sharp corners of the angular particles, and then followed by a stage where densification (overall compression) occurs with much less breakage (Indraratna et al., 2005 and Hossain et al. 2007). However, as the confining pressure is increased considerably, dilation is prevented and the particle assembly undergoes increased compression and associated breakage occurs across the middle part of the grains and not just at the corners (Indraratna et al. 2010 and Indraratna et al. 2014).

The increased breakage from undrained tests may be attributed to an increase in pore water pressure in the micropores that is likely to have caused additional fracture of particles. Coalwash being a relatively weak dual porosity material (Fig. 3), the pore water pressure developed during shearing could be sufficient for the material to degrade. In fact, the critical breakage stress of coalwash is $127 \mathrm{kPa}$ which is relatively 
small compared to natural sandy materials (e.g. 4MPa for Cambria sand). This implies that confining pressure and pore fluid pressure largely govern the undrained strength and breakage characteristics of coalwash. Furthermore, this difference in the breakage characteristics explains the steeper compression slope observed for mean effective pressure exceeding the critical breakage stress $\left(p^{\prime}=127 k P a\right)$ on the $e-\ln$ p’ space.

The mechanism of attaining a peak strength just before particle break and followed by softening that is influenced by breakage was not blatantly observed for coalwash. This indicates that particle breakage occurs over a large stress range upon loading (not just nearing a peak stress), hence the stress-strain response is more progressive or more ductile.

\section{Influence of particle breakage on the critical state}

The experimental results demonstrate that both the particle size distribution of coalwash and the compaction energy level influence the critical state conditions. It was shown that the critical state line position on the compression plane (void ratio vs. mean effective stress) for drained conditions shifts towards the lower void ratio range for relatively large RC levels, i.e. for those specimens having higher compactioninduced breakage (Fig 2a). For the undrained conditions, three ranges were identified, and their transitions were aligned with the incidence of breakage observed predominately during shearing.

On this basis, it seems that the critical state for coalwash is better represented if an additional dimension incorporating particle breakage is considered. In other words, the critical state line on the compression plane $\left(e-\ln p^{\prime}\right)$ can be transformed to a critical state surface through a third dimension representing particle breakage (Fig. 8). 
For describing breakage at or approaching this surface, the total breakage $\left(B_{t}\right)$ that includes degradation during both compaction and shearing is selected.

The critical state surface for the coalwash material in the $e-\ln p^{\prime}-B_{t}$ space is shown in Fig. 8. It is observed here that both drained and undrained critical states define a common planar surface, which when projected to $2 \mathrm{D}$ conforms to the different CSLs shown in Fig. 7a.

Drawing on the laboratory data for both drained and undrained conditions, the expression of the critical state surface (Fig. 8) on the $e-\ln p^{\prime}-B_{t}$ space may be extended from the traditional semi-logarithmic relationship including particle breakage as follows:

$$
e=\Gamma\left(B_{t}\right)-\lambda \ln p^{\prime}
$$

$$
\Gamma\left(B_{t}\right)=\Gamma(0)-\theta_{\Gamma} B_{t}
$$

where, $\Gamma(0)$ is the value of specific void ratio at zero particle breakage, $\theta_{\Gamma}$ is the slope of the critical state surface along the $e-B_{t}$ plane, and $\lambda$ is the slope of the critical state surface slope along the $e-\ln p^{\prime}$ plane. The $\lambda$ and $\theta_{\Gamma}$ are obtained through a best-fit procedure of all the drained and undrained experimental test data at critical state in the three-dimensional $e-\ln p^{\prime}-B_{t}$ space. The proposed surface is represented in Fig. 8 together with experimental results. The values for $\lambda$ and $\theta_{\Gamma}$ of 0.047 and 0.22 , respectively, were found to fit the experimental data well.

\section{Shear and Yielding Behaviour}

Coalwash is a relatively soft crushable granular material that demonstrates a different shear and yielding behaviour to traditionally compacted sands and gravels. A typical critical state shear strength envelope obtained for a specimen compacted at $R C$ of 
95\% is depicted in Fig. 9a. The envelopes for other $R C$ levels (i.e. 90 and 100\%) showed similar results, where the shear strength envelope is linear and the critical state friction angle remains relatively unchanged around $35^{\circ}$ (Fig. 9a). Although the critical state friction angle may be expected to increase with a higher level of compaction, in the case of coalwash, a greater compaction level leads to exacerbated particle degradation, and this in return impedes any significant increase in the critical state friction angle. The increase in $\phi_{\mathrm{cs}}$ for larger RC levels may be attributed to the increase of interparticle contacts in the granular assembly, which results from the incidence of particle breakage during compaction. Furthermore, the $\phi_{\mathrm{cs}}$ of Erksak sand (Been et al., 1991) has been reported to increase with the decrease of critical state void ratio owing to the increase in the interparticle contacts in the assembly. In contrast, a decrease in critical state friction angle has been reported to decrease for ballast due to the 'corner breakage’ of highly angular particles (e.g. Indraratna et al., 2014).

Considering a relatively constant critical state friction angle of $35^{\circ}$ (Fig.6) for $R C$ of $90 \%, 95 \%$ and $100 \%$, the associated critical state stress parameters for compression $\left(M_{c}\right)$ and extension $\left(M_{e}\right)$ could be determined as 1.41 and 0.96 , respectively, using the relationships proposed by Imam et al (2005) defined in the Appendix A. These lines representing $M_{c}$ and $M_{e}$ are plotted together with the stress paths of the specimens prepared at $R C$ of $95 \%$ in Fig. 9b including additional isotropic compression and extension stress path tests (Table 3). The shapes of the corresponding yield envelopes fit the governing equation for anisotropic granular media proposed by Imam et al. (2005). Appendix A gives details of the relevant mathematical formulations of these yield functions and the best-fit parameters for coalwash. As shown in Fig. 10, the experimental data generally fit the theoretical envelopes well for both compression 
and extension domains, except at the high end value of p'> $250 \mathrm{kPa}$ for $\mathrm{RC}=100 \%$. In essence, the yield envelopes for coalwash expand anisotropically with the increasing (i) mean effective stress, $p$ ', and (ii) degree of compaction, without indicating a significant rotation of their orientation (i.e. $\alpha=0.85$ in Fig. 10). The exacerbated particle breakage and accumulated fines caused by high levels of compaction $(R C>90 \%)$ lead to an extremely dense packing arrangement, including micropores that can sustain significant suction compared to a traditional granular fill with larger and interconnected voids. Being a dual porosity material, coalwash cannot be fully saturated even at a back pressure exceeding $150 \mathrm{kPa}$, because, much of the initially occluded air will remain within the intra-particle skeleton. In summary, the inevitable increase in fines due to breakage, and the significant role of micropores within this tight fabric will lead to an expanding yield surface as the value of $R C$ increases from 90\% to100\% (Fig. 10).

\section{Practical applications}

This coalwash material produced in Illawarra collieries has been used in a variety of different sites across the Wollongong region for building transport and other civil infrastructure, e.g. Port Kembla expansion (Chiaro et al, 2014). The results discussed in the previous section revealed that despite substantial breakage, coalwash still meets the stringent performance-based criteria for typical reclamation conditions, whereby the desired apparent friction angle easily exceeds $30^{\circ}$ (Davies et al., 2011). In addition, for typical Port operational conditions where the applied live loads are in the range of 60 to 100kPa (Lai et al., 2011), the shear strength envelopes (Figs. 6 and 9), indicate that this coalwash would have sufficient bearing capacity. For instance, considering an apparent friction angle of $35^{\circ}$ and a strip footing of $300 \mathrm{~mm}$ in width and $600 \mathrm{~mm}$ deep, the allowable bearing capacity with a partial load factor of 2.0 is 
still more than $220 \mathrm{kPa}$. In addition, the field performance of compacted coalwash was evaluated upon compaction using the dynamic cone penetration (DCP) tests (ASTM D6951). A series of post-compaction DCP tests showed that for this coalwash $(R C$ approx. 90\%), DCP values did not exceed a penetration of $12.5 \mathrm{~mm} / \mathrm{blow}$, and on the average were around $8 \mathrm{~mm} /$ blow. This is approximatively equivalent to a California Bearing Ratio (CBR) of about 27 as per the conversion procedure outlined in ASTM D6951, which indicates that despite the incidence of breakage during compaction (i.e. Fig. 2a), coalwash can be favourably compared to a dense sand or gravel in terms of CBR values (Look, 2007) used on transport corridors.

\section{Conclusions}

A series of undrained and drained triaxial shearing tests were conducted to study the impact of breakage on the stress-strain characteristics of coalwash prepared at various relative compaction levels. The following conclusions have been drawn:

1. The experimental results of drained and undrained tests show that the level of compaction energy and the associated initial particle gradation has a significant influence on the stress-strain behaviour of compacted coalwash.

2. A unique critical state relationship between $p^{\prime}$ and $q$ can be defined for drained and undrained conditions and for the different RC levels. The $p^{\prime}$ and $q$ relationship is linear showing a critical stress ratio $\left(M_{c}\right)$ of 1.41 and critical state friction angle $\left(\phi_{\mathrm{cs}}\right)$ of $35^{\circ}$.

3. A family of CSLs can be defined for different RC levels in the $e$-ln $p$ ' plane, with a progressive shift towards the lower void ratios (i.e. broader particle grading for higher RC levels). This shows that from a practical point of view, due caution must be exercised in the field when analysing the long term stability of coalwash, 
particularly in line with common end-product specifications, where quality control relies mainly on the dry unit weight (i.e. RC levels >95\%). The specimens prepared at RC level of 95 and $100 \%$ showed a substantial difference in the shearing and breakage behaviour, despite being both classified as prescribing to typical field placement criteria.

4. The undrained CSL of coalwash was found to be linear with two transition points on the $e-\ln p^{\prime}$ space, on which three regions could be distinguished by a marked change in the slope. The most notable change in undrained CSL slope was observed for effective stress level of $127 \mathrm{kPa}$, defined as the critical breakage stress. Upon reaching this value, the particle breakage is significantly exacerbated. Therefore, the determination of this critical breakage stress level for any similar washery discard is vital to prevent excessive particle breakage and associated deformation during service.

5. The ratio between total and compaction induced breakage remains approximately constant in the low effective mean pressure range $\left(p^{\prime}<50 \mathrm{kPa}\right)$ but differs quite considerably for larger mean effective pressures due to a predominance of shearing induced breakage.

6. The mechanical response of coalwash is influenced by the particle breakage which differs for drained and undrained shearing. Results showed that while that CSL shows distinct lines for drained and undrained shearing in the compression plane $\left(e-\ln p^{\prime}\right)$, all critical states fall on the same $e-\ln p^{\prime}-B_{t}$ surface.

7. The yielding behaviour of coalwash could be described reasonably well with an expanding anisotropic yield surface model with increasing relative compaction (RC), albeit some discrepancies with experimental data at large values of $p^{\prime}$ for $R C=100 \%$, and this could be attributed to particle breakage. It was perceived 
(although not measured) that the micropores together with the generation of fines upon breakage and their subsequent compaction within a tight fabric would sustain significant suction contributing to increased shear strength.

8. From a practical perspective, the coalwash exhibited sufficient bearing capacity and internal friction angle to meet the common performance-based criteria for typical reclamation. In addition, field DCP results demonstrated that compacted coalwash could be compared favourably to dense sands and gravels in terms of expected values of CBR.

\section{Acknowledgement}

The authors gratefully acknowledge the financial assistance provided by the Australian Research Council, Coffey Geotechnics, Douglas Partners, Menard Bachy and Port Kembla Port Corporation. The authors also appreciate the support of BHP Illawarra Coal for supplying the coalwash for this study. The assistance provided by Dr Gabriele Chiaro during the initial stages of the ARC project and by Mr. Alan Grant and Mr. Ian Laird in the execution of tests reported herein is gratefully appreciated.

\section{Appendix A}

While there are numerous studies conducted on the yielding of granular fills (e.g. Taiebat and Dafalias, 2008), a summary of the governing equations capturing anisotropic yielding is given by the following equations (Imam et al., 2005).

$$
\begin{gathered}
f=(\eta-\alpha)^{2}-M_{\alpha}^{2}\left[1-\left(\frac{p}{p_{0}}\right)^{1 / 2}\right]=0 \\
M_{\alpha}=\sqrt{(k M-\alpha)(M-\alpha)} \\
M_{c}=\frac{6 \sin \phi_{c s}}{3-\sin \phi_{c s}} ; M_{e}=\frac{6 \sin \phi_{c s}}{3+\sin \phi_{c s}}
\end{gathered}
$$


where, $\eta$ is stress ratio, $\phi_{c s}$ is the critical state friction angle, $\alpha$ is the rotation gradient of yield surface with respect to its hydrostatic axis, and $k$ is the parameter representing the shape of the yield surface. For this coalwash, the best-fit parameters for RC $=90 \%, 95 \%$ and $100 \%$ are listed in Table 4 . While $k$ takes a value in the order of 5 for liquefiable sands (Imam et al., 2005), for coalwash $k$ varies between 1.5 and 2.7. The pseudo-hydrostatic axis is defined as the line of constant stress ratio on which the peak value of the mean effective stress $p^{\prime}$ lies. The values of $M_{c}$ and $M_{e}$ are functions of the critical state friction angle $\left(\phi_{c s}\right)$ as obtained from triaxial compression and extension tests (Eqns. A2 and A3). 


\section{References}

ASTM (2009). Standard Test Method for Use of the Dynamic Cone Penetrometer in

Shallow Pavement Applications. ASTM standard D6951/D6951M - 09 Annual

Book of Standards. West Conshohoken, PA., American Society of Testing Materials.

Bedin, J., Schnaid, F., Da Fonseca, A. V. and Costa Filho, L. D. M. (2012). Gold tailings liquefaction under critical state soil mechanics. Geotechnique, 62(3), pp. 263267.

Been, K., Jefferies, M. G. and Hachey, J. (1991). The critical state of sands. Geotechnique, 41(3), pp. 365-381.

Blunden, B. \& Gray, A. (2006). Coal Wash data and Product Specification: fill. BHP Billiton- Illawarra Coal, Processing and Logistics, Nov, 31p.

Canibano, J. G., Garcia, M. and Valcarce, J. F. (1990). Construction of a roadbase using coal wastes stabilized with cement. Proceedings of the third international symposium on the reclamation, treatment and utilization of coal mining wastes. Glasgow, U.K., pp. 17-23.

Carrera, A., Coop, M. and Lancellotta, R. (2011). Influence of grading on the mechanical behaviour of stava tailings. Geotechnique, 61(11), pp. 935-946.

Chiaro, G., Indraratna, B., Tasalloti, S. M. A. and Rujikiatkamjorn, C. (2014). Optimisation of coal wash - slag blend as a structural fill. Ground Improvement Journal, ICE 168(1), 33-44.. 
Davies, P., Philip, R. E. D. and James, D. M. (2011). Geotechnical design for the Port Botany expansion project, Sydney. Proceedings of the Institution of Civil Engineers. Geotechnical engineering 164(9), pp. 149 -167.

Fityus, S., Hancock, G. \& Wells, T., (2008). Geotechnical characteristics of coal mine spoil. Australian Geomechanics 43(3), pp.13-22.

Garga, V. K. and Zhang, H., (1997). Volume changes in undrained triaxial tests on sands. Canadian Geotechnical Journal, 34(5), pp. 762-772.

Heitor, A., Indraratna, B. and Rujikiatkamjorn, C. (2013). Laboratory study of smallstrain behavior of a compacted silty sand. Canadian Geotechnical Journal, 50(2), pp. 179-188.

Hossain, S., Indraratna, B., Darve, F., Thakur, P. (2007) DEM analysis of angular ballast breakage under cyclic loading. Geomechanics and Geoengineering: International Journal, 2 (3), pp. 175-182.

Imam, S. M. R., Morgenstern, N. R., Robertson, P. K. and Chan, D. H. (2005). A critical-state constitutive model for liquefiable sand. Canadian Geotechnical Journal 42(3), pp. 830-855.

Indraratna, B., Wijewardena, L. S. S. and Balasubramaniam, A. S. (1993) Large-scale triaxial testing of greywacke rockfill. Geotechnique 43(1), pp. 37-51.

Indraratna, B., Gasson, I. and Chowdhury, R. N. (1994). Utilization of compacted coal tailings as a structural fill. Canadian Geotechnical Journal, 31, pp. 614-623. 
Indraratna, B., Lackenby, J. and Christie, D. (2005). Effect of confining pressure on the degradation of ballast under cyclic loading. Geotechnique, 55(4), pp. 325-328.

Indraratna B., Thakur P. K. and Vinod J. S. (2010). Experimental and Numerical Study of Railway Ballast Behaviour under Cyclic Loading. International Journal of Geomechanics, 10(4), pp. 136-144.

Indraratna, B., Sun, Q. D. \& Nimbalkar, S., (2014). Observed and predicted behaviour of rail ballast under monotonic loading capturing particle breakage. Canadian Geotechnical Journal, 52(1), pp. 73-86.

Kaliboullah, C. I., Indraratna, B., Rujikiatkamjorn, C., \& Heitor, A., (2015). Evaluation of coalwash as a potential structural fill material for port reclamation. Proceedings of the 12th Australia New Zealand Conference on Geomechanics (ANZ 2015), Wellington, pp. 199-206.

Karner, S. L., Chester, F. M., Kronenberg, A. K. \& Chester, J. S., (2003). Subcritical compaction and yielding of granular quartz sand. Tectonophysics, 377(3-4), pp. 357381.

Kettle, R. J., (1983). The improvement of colliery spoil. Quarterly Journal of Engineering Geology, 16 (3), pp. 221-229.

Kikumoto, M., Wood, D. M. and Russell, A. (2010). Particle crushing and deformation behaviour. Soils and Foundations, 50 (4), pp. 547-563.

Lai, Z., Hsi, J., Rheinberger, T. and Andrews, T. (2011). Geotechnical offshore site investigation and reclamation design at Port Kembla. Proceedings of Australian 
Geomechanics Society Sydney Symposium, Coastal and Marine Geotechnics: Foundations and Trade, Sydney, pp. 61-72.

Leventhal, A. (1996). Coal washery reject as an engineered material. Proceedings of the National Symposium on the use of Recycled Materials in Engineering Construction Sydney, Australia, pp. 54-59.

Look, B. G. (2007). Handbook of geotechnical investigation and design tables, Taylor \& Francis., 58p.

Lu, G. Q. and Do, D. D. (1992). Physical structure and adsorption properties of coal washery reject. Fuel, 71(7), pp. 809-813.

Montgomery, D. G. (1990). Utilisation of coal washery wastes in engineering construction. International Coal Engineering Conference (Sydney, NSW). Barton, ACT: Institution of Engineers, Australia, pp. 79-83.

Rujikiatkamjorn, C., Indraratna, B. and Chiaro, G. (2013). Compaction of coal wash to optimise its utilisation as water-front reclamation fill. Geomechanics and Geoengineering, 8 (1), pp. 36-45.

Russell, A. R. and Khalili, N. (2004). A bounding surface plasticity model for sands exhibiting particle crushing. Canadian Geotechnical Journal 41, pp. 1179-1192.

Seddon, K. D., Leventhal, A. R. A. and Miller, S. D., (1987). Geotechnical and geochemical testing for the characterisation of coal washery wastes. Proceedings of the International Conference on Mining and Industrial Waste Management, Pretoria, South Africa, pp. 253-264. 
Skarżyńska, K. M. (1995). Reuse of coal mining wastes in civil engineering — part 1: Properties of minestone. Waste Management, 15(1), pp. 3-42.

Standards Australia (2003). Method for testing soils for engineering purposes - soil compaction and density tests - determination of the dry density/moisture content relation of a soil using standard compactive effort. Australian Standard AS 1289.5.1.1 - 2003, Sydney.

Taiebat, M. and Dafalias, Y. F. (2008). SANISAND: Simple anisotropic sand plasticity model. International Journal for Numerical and Analytical Methods in Geomechanics 32(8), pp. 915-948.

Tasalloti, S.M.A., Indraratna, B., Rujikiatkamjorn, C., Heitor, A. and Chiaro, G. (2015) A laboratory study on the shear behavior of mixtures of coal wash and steel furnace slag as potential structural fill, Geotechnical Testing Journal, ASTM, 38(4), 361-372.

Wood, D. M. and Maeda, K. (2008). Changing grading of soil: Effect on critical states. Acta Geotechnica, 3(1), pp. 3-14.

Yamamuro, J. and Lade, P., (1996). Drained sand behavior in axisymmetric tests at high pressures. Journal of Geotechnical Engineering, 122 (2), pp. 109-119. 


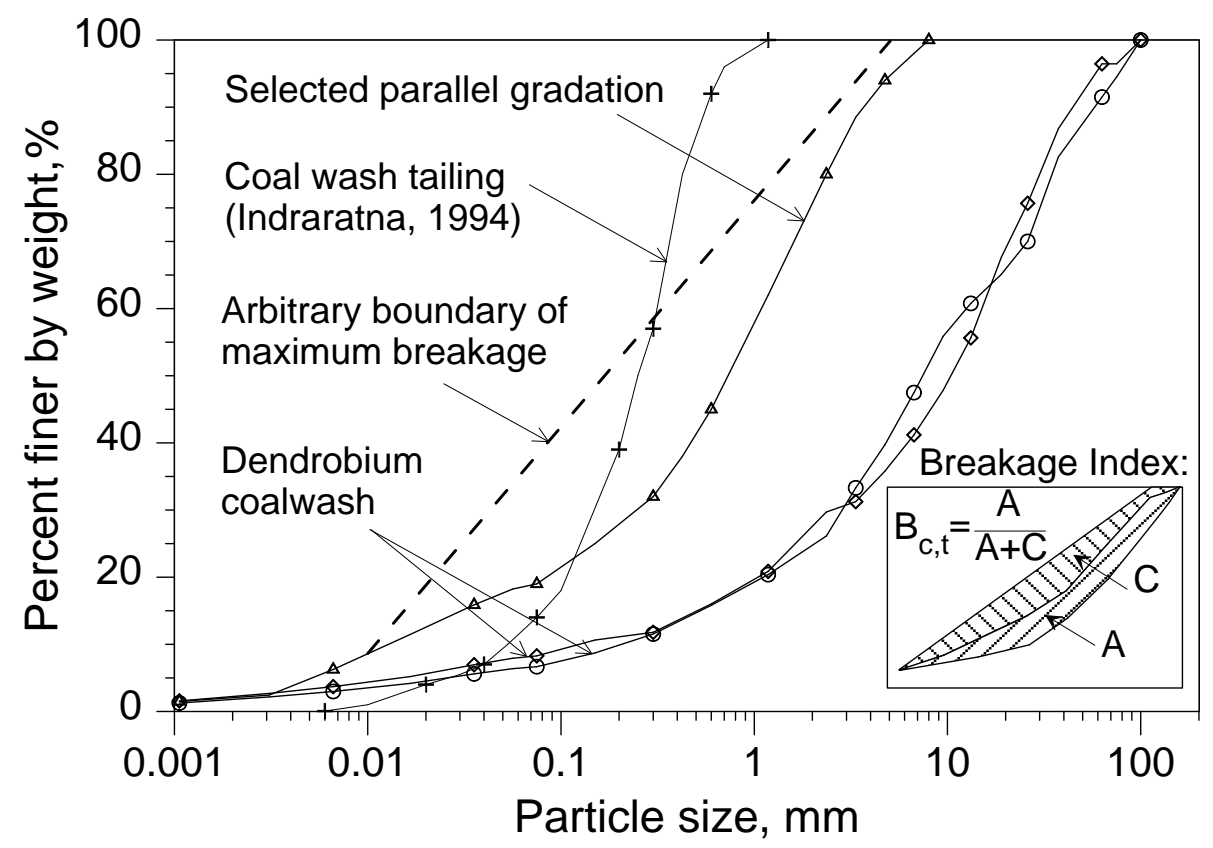

Fig. 1. Particle size distribution curves for coalwash used for this study. 

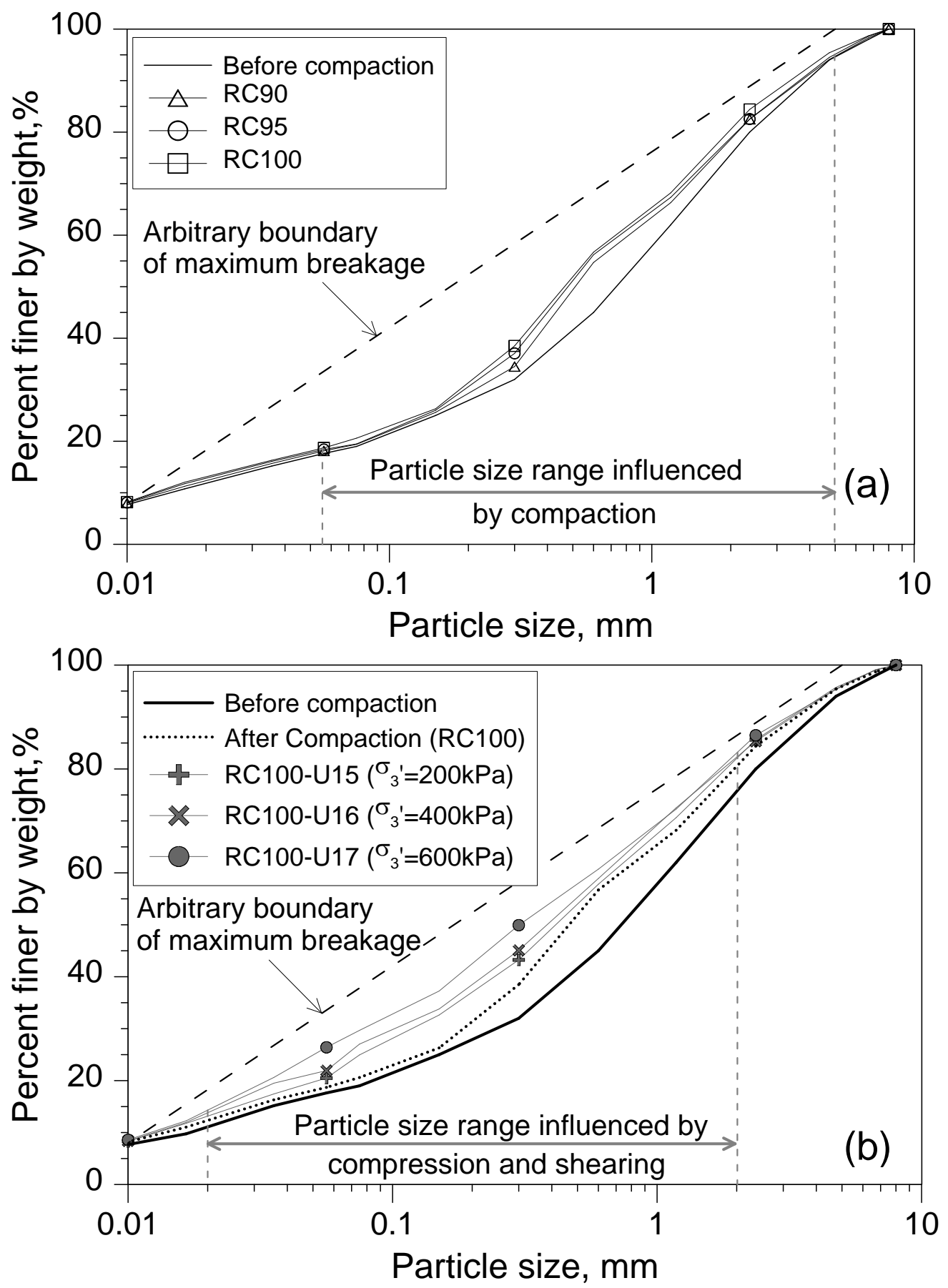

Fig. 2. Typical PSD curves used to quantify particle breakage (a) after compaction for different energy levels and (b) after undrained shearing for different effective confining pressures. 

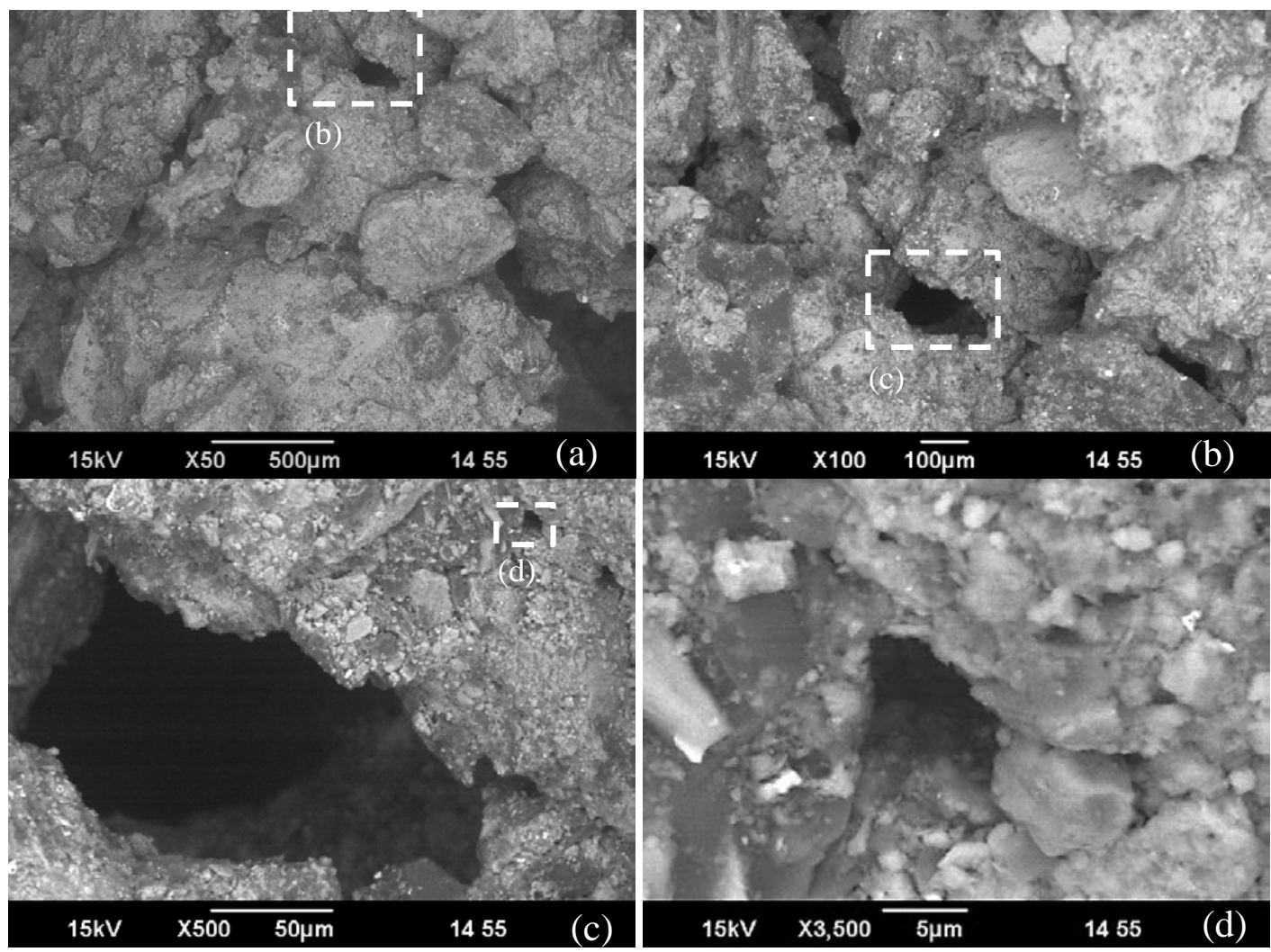

Figure 3. SEM micrographs of coalwash compacted at an RC level of 95\% showing micropores with magnification of (a) 50X, (b)100X, (c) 500X and (d) 3500X. Marked regions indicate positions of (b, c and d) zoomed images. 


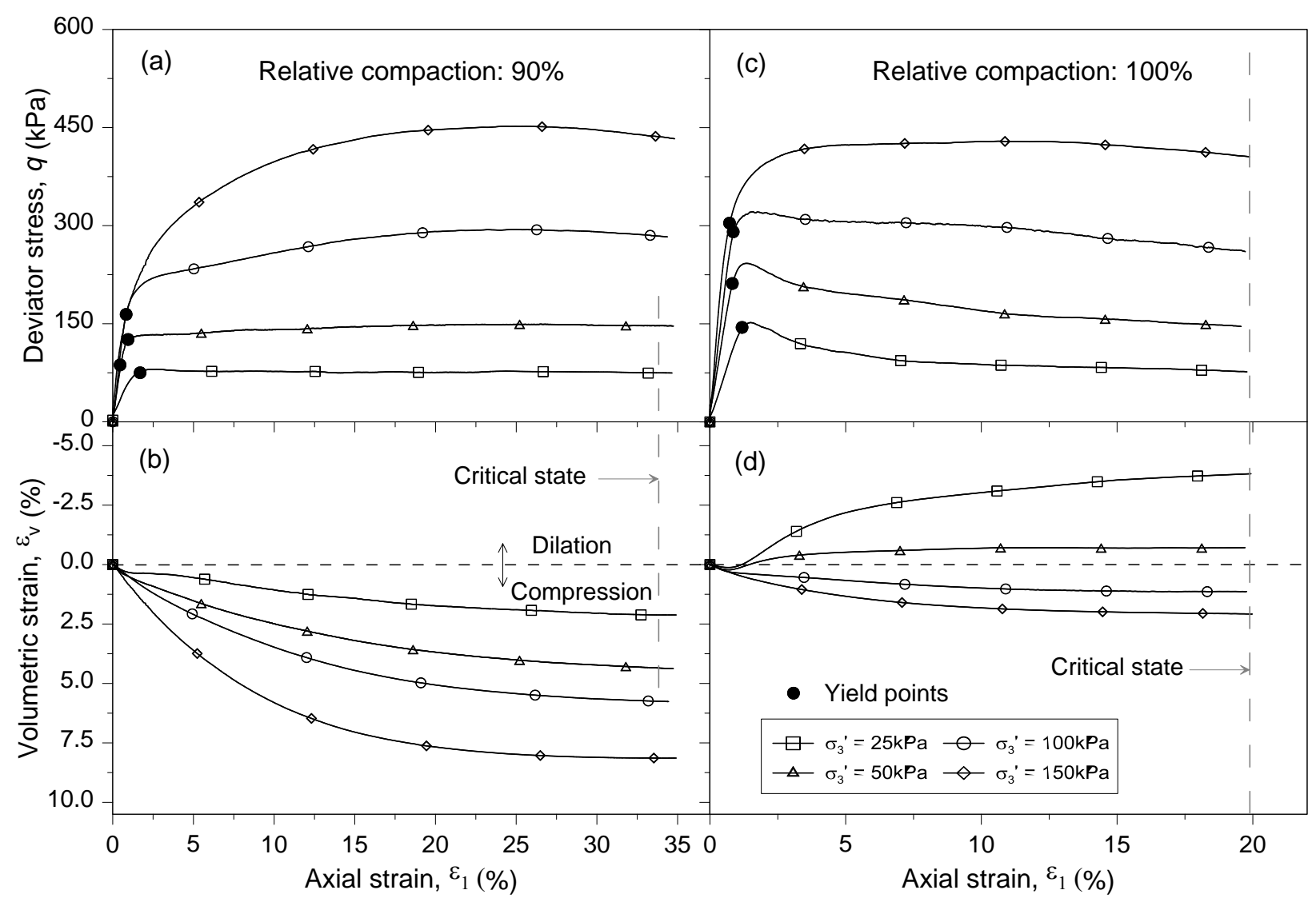

Fig. 4. Drained shear results for compacted coalwash prepared at 90and 100\% relative compaction: (a and c) deviator stress; and (b and d) volumetric strain, respectively. 


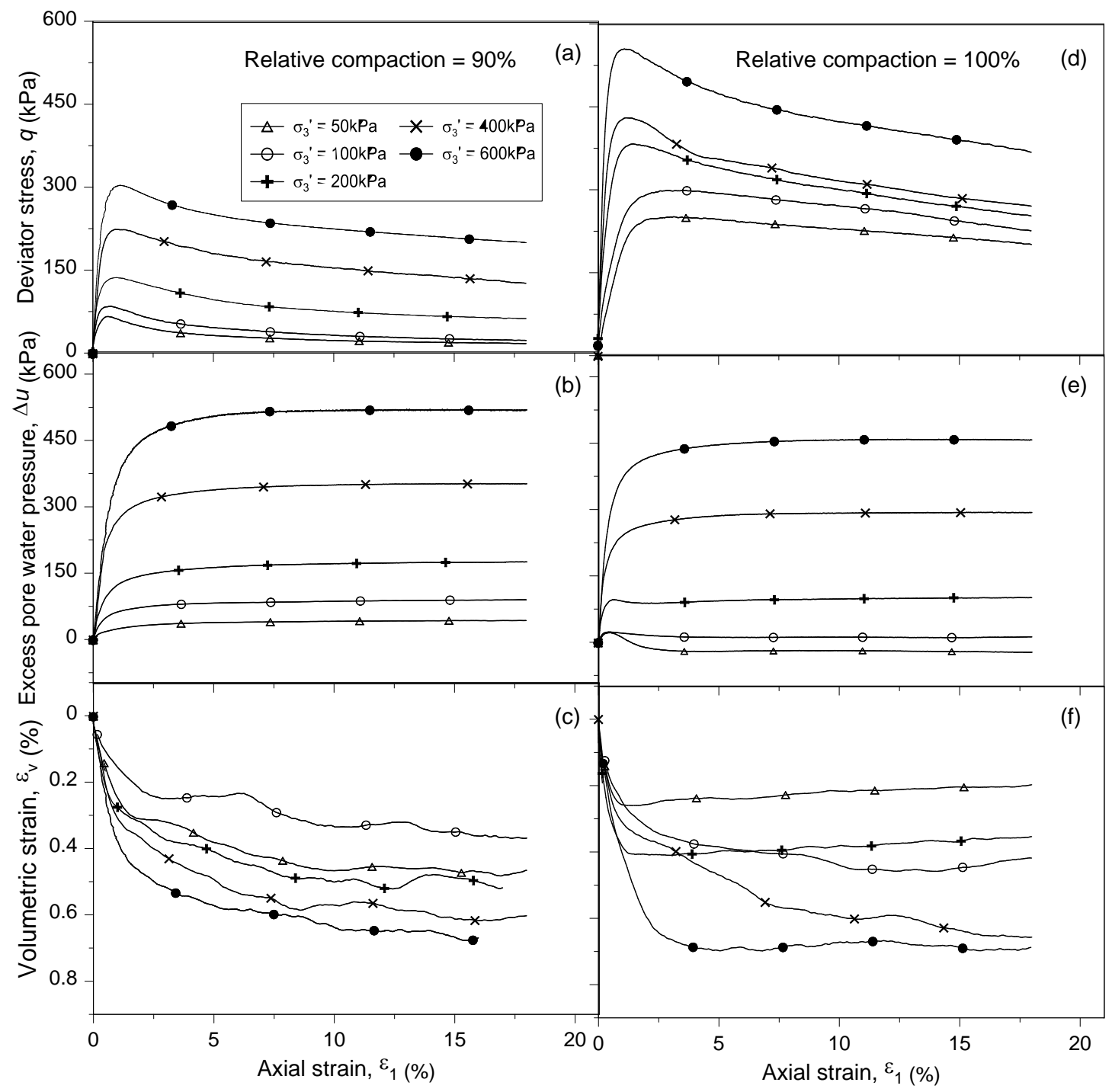

Fig. 5. Undrained shear results for compacted coalwash prepared at 90and 100\% relative compaction: (a \& d) deviator stress; (b \& e) excess pore water pressure; and (c \& f) volumetric strain, respectively. 


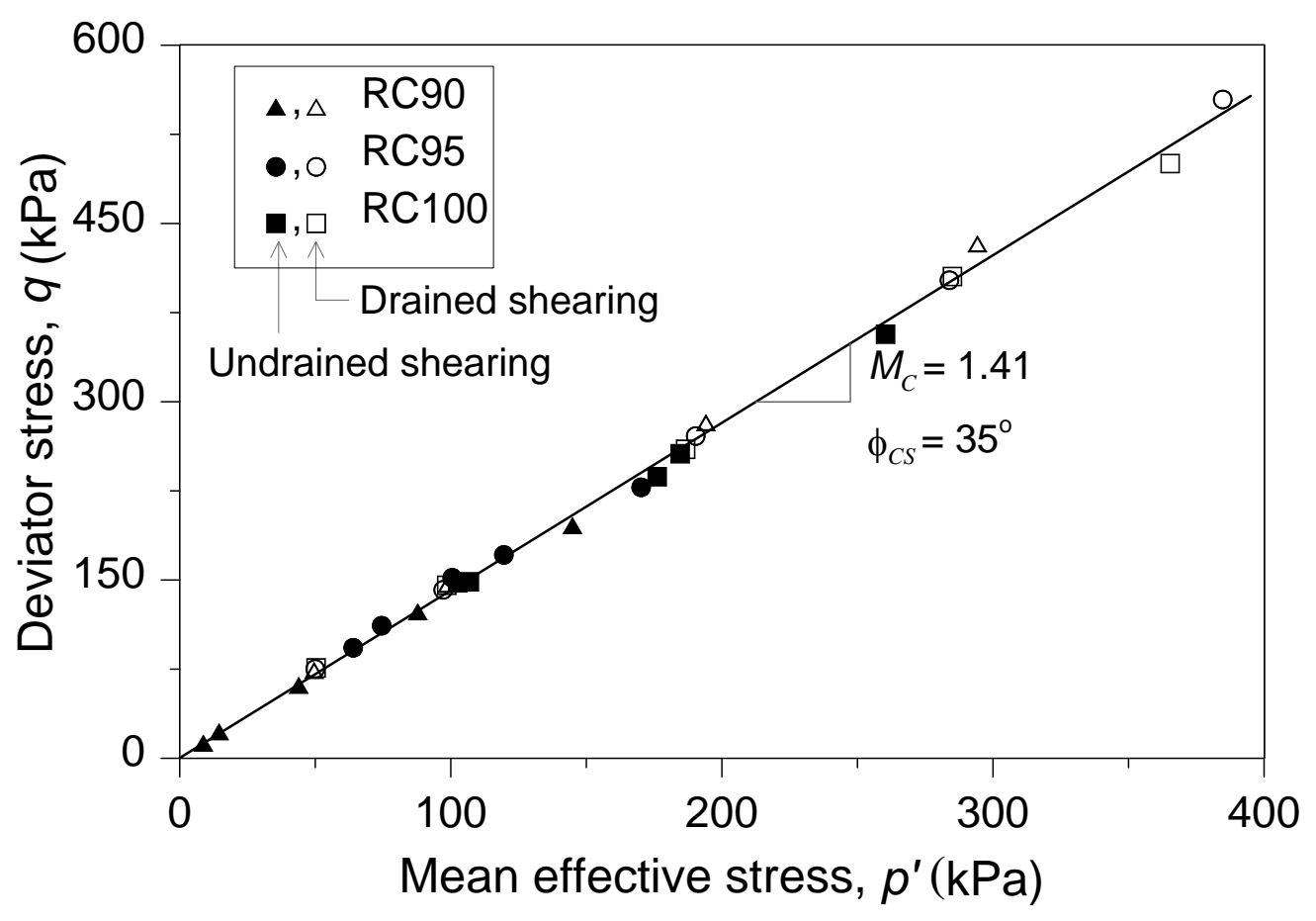

Fig. 6. Critical state line of compacted coalwash in $q-p^{\prime}$ space. 

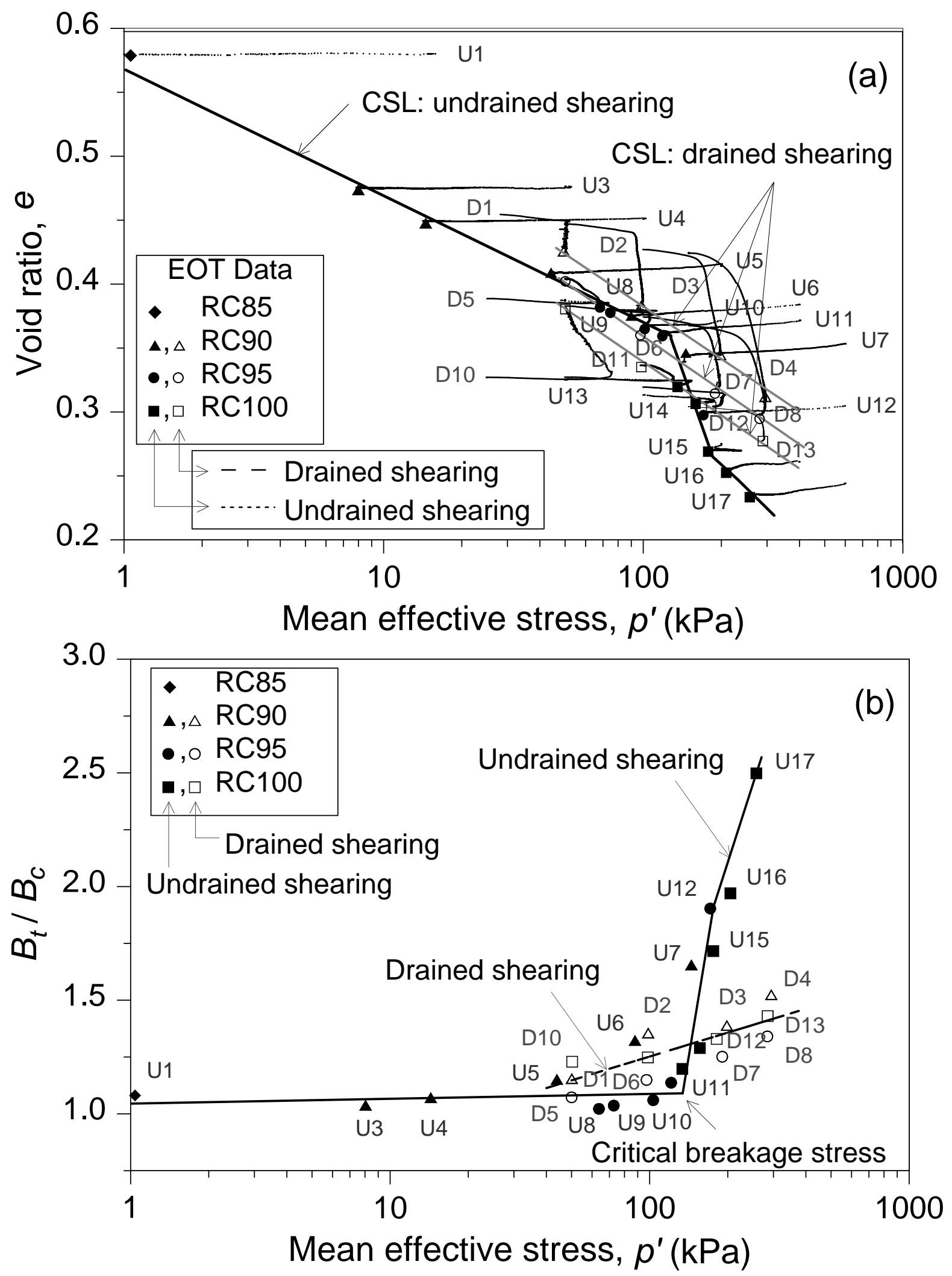

Fig. 7. Critical state of compacted coalwash (a) in terms of $e-\ln p^{\prime}$ and (b) breakage 


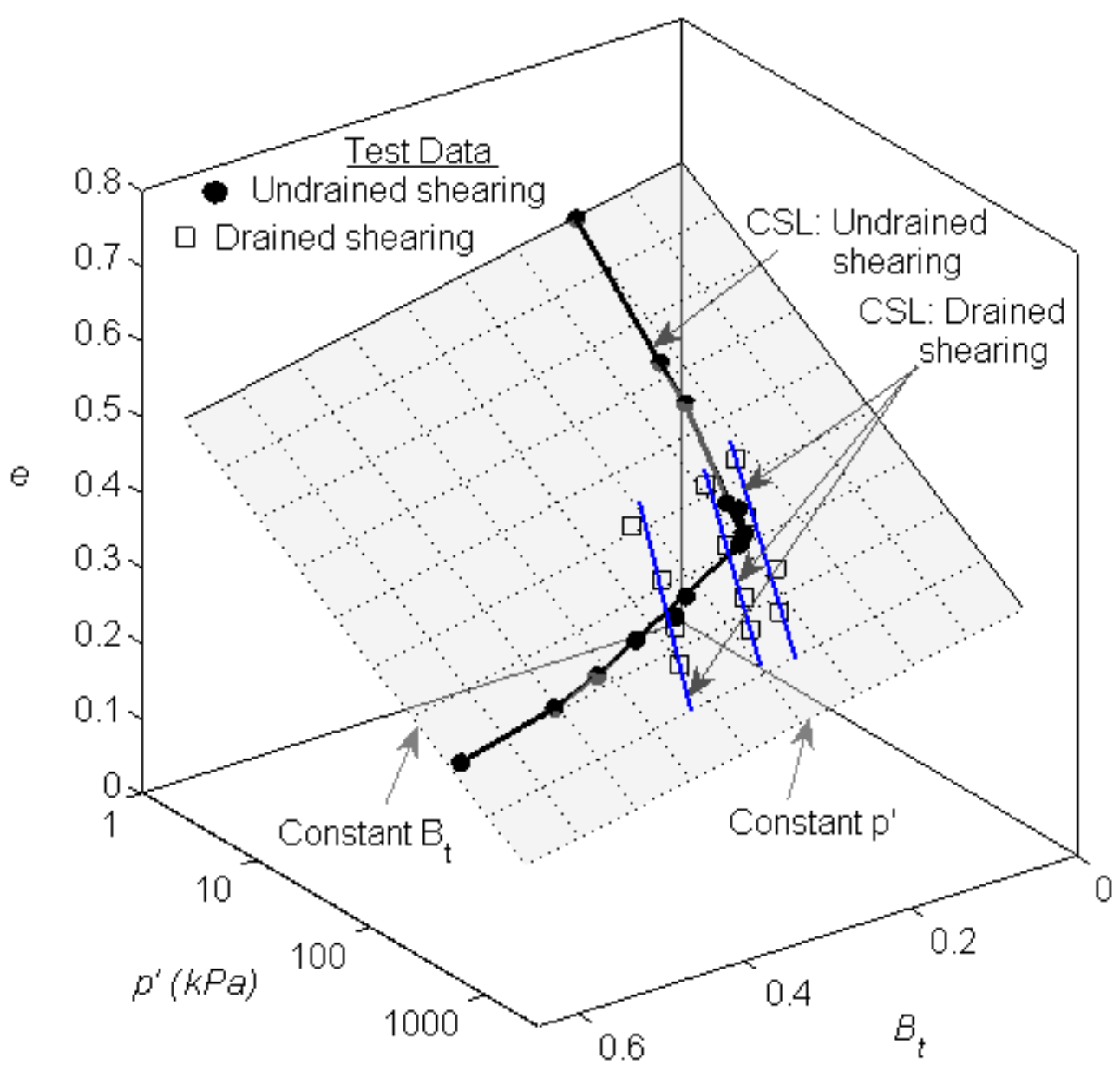

Fig. 8. Critical state surface of compacted coalwash in $e-\ln p^{\prime}-B_{t}$ space. 

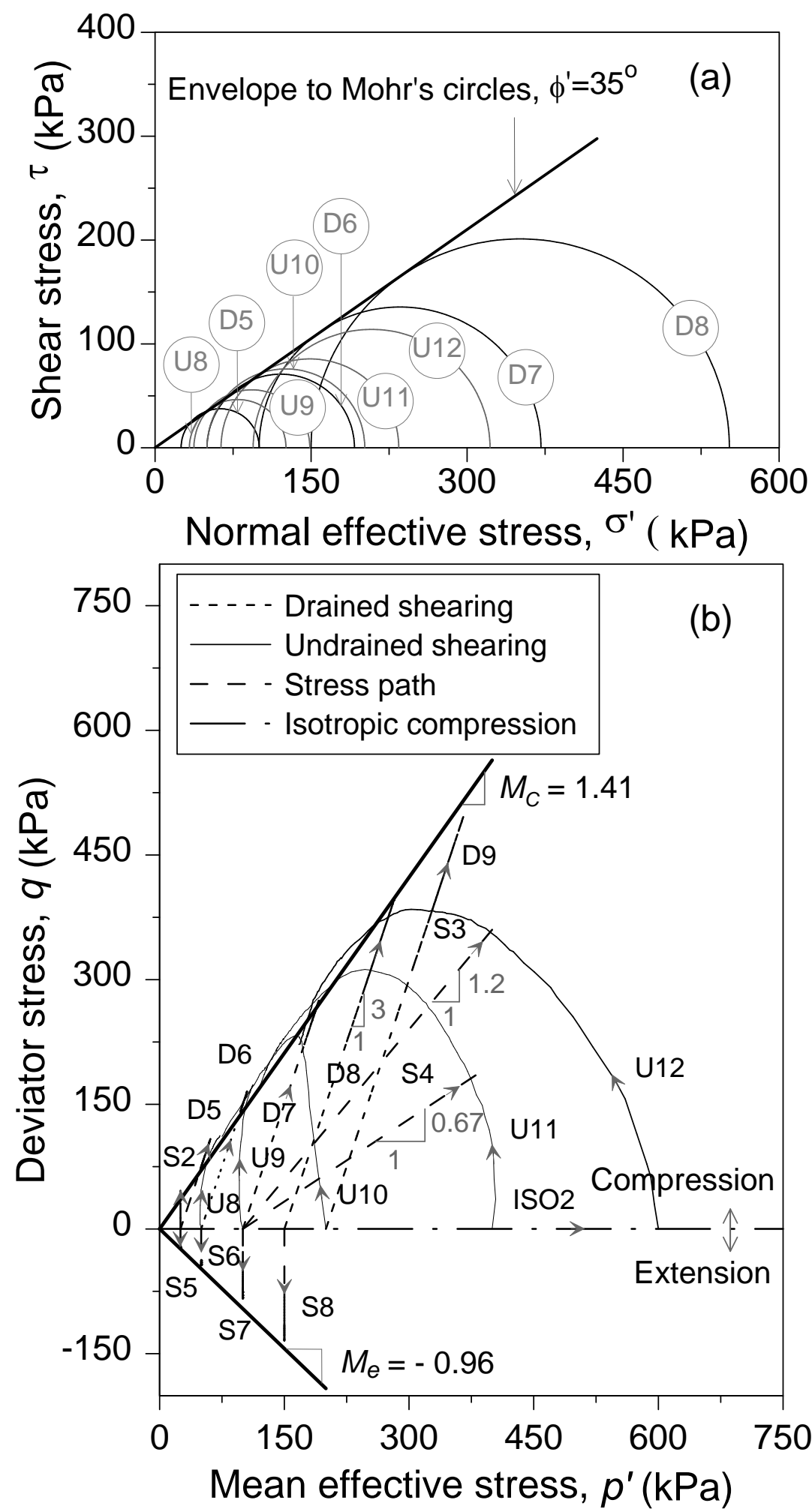

Fig. 9. Shear strength data of specimens compacted at RC=95\% (a) Mohr circles at critical state and (b) stress paths in compression and extension. 


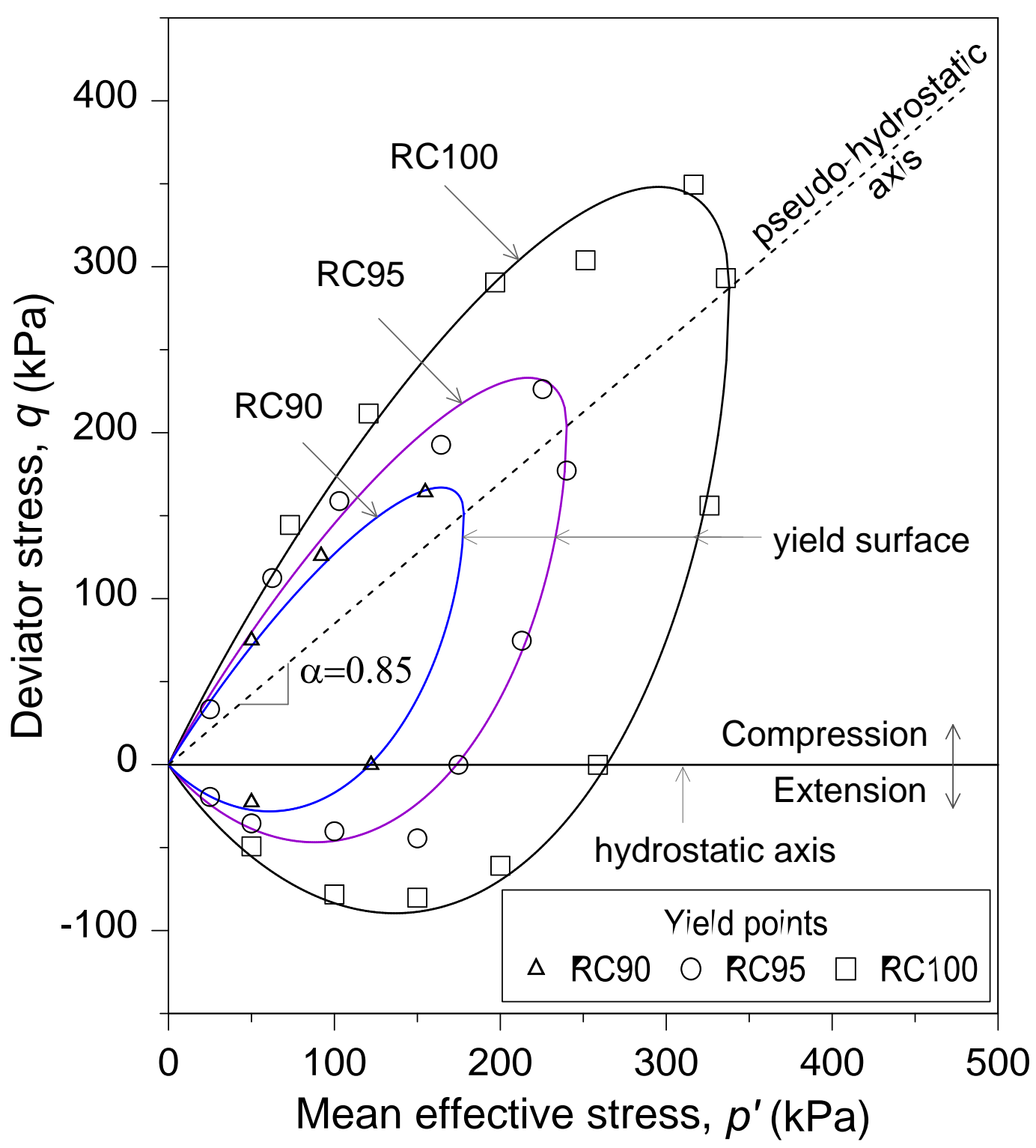

Fig. 10. Yielding behaviour of compacted coalwash for different levels of relative compaction. 